\title{
The decay of short-term implicit memory: Unpacking lag
}

\author{
ELINOR MCKONE \\ Australian National University, Canberra, Australian Capital Territory, Australia
}

\begin{abstract}
McKone (1995) reported a short-lived repetition priming effect, superimposed on long-lived priming. This short-term implicit memory survived a few intervening items and several seconds for words but decayed precipitously for nonwords, producing a lag $\times$ lexicality interaction. Here, mechanisms of decay are studied by disconfounding the time delay and interference components of lag. In Experiment 1 , time delay was varied while number of intervening items was held constant, and vice versa. In Experiment 2, priming was plotted as a function of time delay, with and without intervening items. Using a lexical decision task, both experiments found independent contributions of time and interference to the decay of short-term priming. Further, Experiment 2 attributed the lag $\times$ lexicality interaction to a particular sensitivity of nonword traces to interference. An illustration of how these effects might arise in the word recognition system is provided.
\end{abstract}

In studies of repetition priming, it is found that a repeated stimulus is more easily processed on its second presentation than on its first. For example, word-nonword decision times in a lexical decision task are faster to repeated items (see, e.g., Kirsner \& Smith, 1974; D. L. Scarborough, Cortese, \& H. S. Scarborough, 1977), as are reading-aloud times in a naming task (see, e.g., Monsell, 1985). It has been argued that such priming effects reflect the operation of implicit memory, as defined by Graf and Schacter (1985), in that the nature of the retrieval from memory is automatic and involuntary rather than deliberate and controlled. By this definition, implicit retrieval does not rely on conscious recollection of the target's initial presentation and is independent of any such recollection that might occur. The form of repetition priming that has received the most attention in the literature is a long-lived form that has been shown to endure for many minutes, hours, or days. This long-term priming effect is not of direct interest here (for reviews, see Roediger \& McDermott, 1993; Schacter, 1987; Tenpenny, 1995). Instead, the focus of the present work is on a more recently identified repetition effect, which will be referred to as short-term priming.

In McKone (1995), I reported work demonstrating short-term priming for visually presented words and nonwords (see, also, Maljkovic \& Nakayama, 1994, for an

This research was conducted as part of the requirements for a PhD degree at the Australian National University and was supported by an A.N.U. Graduate School scholarship. Preparation of the paper was supported by Grant F96058 from the Australian Research Council. I thank supervisors Michael Cook and Judith Slee for their input and also Jay Rueckl, Michael Kahana, and an anonymous reviewer for valuable feedback on earlier versions of this manuscript. Correspondence concerning this article should be addressed to E. McKone, Division of Psychology, Australian National University, ACT 0200, Australia (e-mail: elinor.mckone(a.anu.edu.au). effect of similar duration with very different stimuli). In those experiments, a repetition benefit, enduring up to several seconds and with a few intervening items, was found, superimposed on the standard long-term priming effect. The duration of this short-lived priming effect was comparable with that of explicit short-term memory, as revealed in memory span and serial recall tasks (see, e.g., Miller, 1956; Waugh \& Norman, 1965). It was, however, demonstrated with tasks assumed to benefit from implicit retrieval of the target's prior presentation (lexical decision and naming) rather than with tasks requiring conscious recollection. Thus, the label short-term implicit memory was selected to describe the duration of the effect and the presumed nature of the retrieval. (No assumption is made that short-term priming necessarily reflects a separate memory system.)

\section{Evidence for Short-Term Implicit Memory}

Studies investigating short-lived repetition priming have employed a lag paradigm. With this method, a continuous list of trials is presented, and the subject is required to respond to every trial. Particular stimuli are repeated at various lags, by varying the number of trials (and thus also the time delay) intervening between target repeats. Priming is then calculated as the reaction time advantage on second presentation, as compared with the first, and plotted as a function of lag.

In several past studies, the lag approach has been used to examine priming in lexical decision (see, e.g., Bentin \& Moscovitch, 1988; Kersteen-Tucker, 1991; Kirsner \& Smith, 1974; Monsell, 1985; Ratcliff, Hockley, \& McKoon, 1985; Scarborough et al., 1977). These studies were reviewed in some depth in McKone (1995). Briefly, these studies demonstrated a clear Lag 0 priming effect, in which priming with no intervening items was noticeably greater than priming at longer delays. They were unclear, however, 
as to whether this priming effect lasted beyond Lag 0 and so constituted a short-term effect analogous to short-term explicit memory (at least in duration). Some form of decay over lag was generally obtained but was often either not significant or not tested for significance. Previously, I suggested that there were at least three possible reasons for the failure to find consistent evidence of short-term priming beyond Lag 0-namely, (1) a possible lack of power of some studies, with small numbers of items per condition or small numbers of subjects; (2) the apparent failure in some experiments to rotate target items through conditions, leaving priming at particular lags open to itemspecific effects; and (3) the use of slow presentation rates in some studies, thus potentially allowing a short-term effect to have largely dissipated by Lag 1 or Lag 2 .

In McKone (1995), I examined priming in lexical decision and naming tasks as a function of lag, using 20 items per condition, 18 subjects per experiment, proper cycling of items through conditions, and a fast 2-sec-peritem presentation rate. Under these conditions, a shortterm priming effect was demonstrated, which endured for up to 3 intervening items and $8 \mathrm{sec}$ between repeats. This short-term priming is shown in Figure 1, which plots priming for words (low frequency) and nonwords (pseudowords such as mave) in lexical decision. One striking feature of the priming patterns is the strong lag $\times$ lexicality interaction: Whereas short-term priming decayed smoothly over a few trials for real words, priming for nonwords dropped precipitously to (or possibly even below) the long-term value with a single intervening item. This lag $\times$ lexicality interaction is of key importance to the present work and will be returned to shortly.

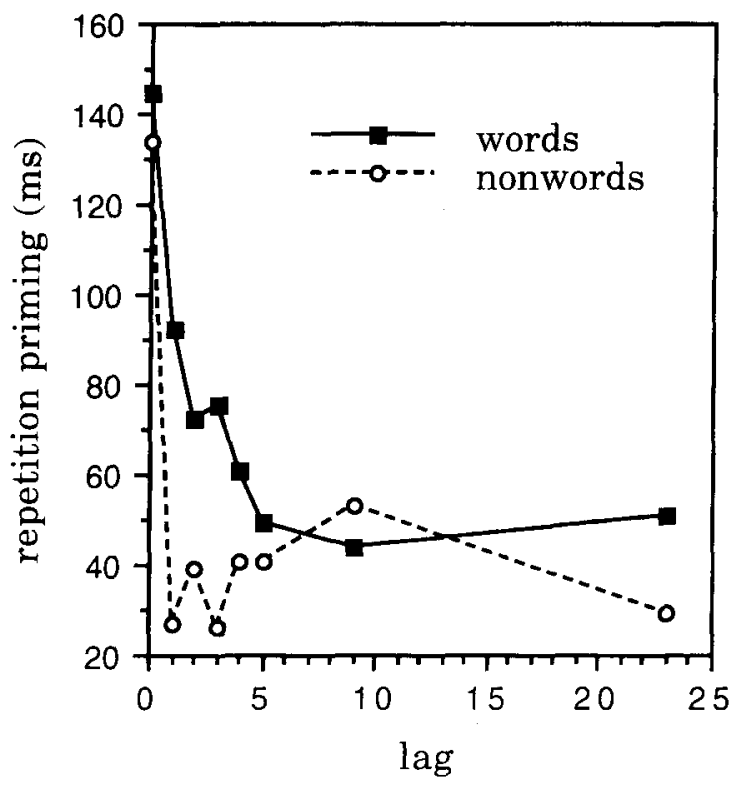

Figure 1. Results of Experiment 1 of McKone (1995), showing the lag $\times$ lexicality interaction. The stimuli were low-frequency words and pseudowords, and the task was lexical decision. The same form of interaction was obtained with a naming task.
McKone (1995) provided evidence that short-term implicit memory does not simply reflect either of two wellestablished memory forms -namely, long-term implicit memory and short-term explicit memory. The clearest evidence that short-term priming can be distinguished from long-term priming was that, for very high frequency words, short-term priming was found to exist in the absence of long-term priming (i.e., priming reached zero beyond approximately Lag 4). Further, short-term priming for high-frequency words was of the same magnitude and had the same decay rate as that for low-frequency words; the manipulation of word frequency simply reduced total priming at short lags by a constant equal to the difference in long-term priming between low- and high-frequency words. This suggests that short-term and long-term priming are independent and additive; thus, it is assumed that long-term priming is present at all lags and that an additional contribution from short-term implicit memory is available prior to, perhaps, Lag 4 .

With respect to the distinction of short-term priming from explicit memory, it was shown that the decay patterns of explicit recognition (old-new decision) did not match those in the tasks assumed to elicit implicit retrieval (i.e., lexical decision and naming); specifically, there was no lag $\times$ lexicality interaction. Recognition decisions were also found to be substantially slower than lexical decision and naming responses, suggesting that any explicit recall of earlier items was unlikely to be responsible for the repetition advantage on the implicit tasks. (This is not to say that subjects did not explicitly recognize repeats of earlier items but simply that this information arrived too late to assist in making the lexical decision or naming response. See Hintzman and Caulton, 1995, for a direct demonstration that, in long-term priming at least, information sufficient to make an accurate lexical decision to a repeated item becomes available much earlier in processing than does information sufficient to make an accurate old decision.)

\section{The Lag $\times$ Lexicality Interaction}

The interaction between lag and lexicality demonstrated in Figure 1 appears to locate the short-term priming effect as arising from transient changes somewhere within the word recognition system. ${ }^{1}$ It is only at the level of lexical structure that words and pseudowords differ and, thus, that the manipulation of lexicality becomes psychologically meaningful. At lower levels of processing (e.g., visual form or letter processing), words and pseudowords are equivalent stimuli. Thus, the lag $X$ lexicality interaction suggests the locus of short-term priming is at a lexical level, where lexical is used to refer to whatever internal knowledge we might have about the orthography, phonology, or semantics of English. Such knowledge might well include localized whole-word representations (see, e.g., McClelland \& Rumelhart, 1981), part-word as well as whole-word representations (see, e.g., Taft, 1991), or distributed representations in which whole-word units are not clearly distinguishable at all (see, e.g., Seidenberg \& McClelland, 1989). 
The lag $\times$ lexicality interaction is of interest, then, because it appears to require that traces left within the word recognition system (e.g., transient activations) are in some way weaker for nonwords than for real words. One of the aims of the present experiments was to explore in more detail the exact way in which nonword traces are weaker. Before this can be attempted, however, a potential problem with the lag $\times$ lexicality interaction must be addressed.

The results presented in Figure 1 show repetition priming in a lexical decision task. It is now well recognized that, for long-term priming at least, the lexical decision task can underestimate the residual effect of prior presentation for nonwords (for a discussion, see Bowers, 1994; Dorfman, 1994; Feustel, Shiffrin, \& Salasso, 1983). The argument here is that, when a nonword is repeated, prior presentation might speed the access stage of lexical decision (i.e., a primed stimulus is resolved or identified more quickly) but might simultaneously slow the decision phase (i.e., the primed stimulus is now more familiar and so is more difficult to reject as a word), thus leading the observed priming value to underestimate the strength of the residual trace. With respect to the patterns of short-term priming, it is a logical possibility that an interaction between lag and lexicality might arise because priming effects decay at different rates for the access and decision components of the lexical decision task (i.e., for nonwords, the decision disadvantage takes over from the access advantage, whereas, for words, these always act in the same direction).

Although this is a logical possibility, the empirical evidence suggests that it is not the case. First, the interaction demonstrated in Figure 1 was replicated in McKone (1995) with a naming task. Naming is commonly assumed to share lexical access procedures with lexical decision, but it clearly differs in its decision requirements (Andrews, 1992). In particular, opposite decisions are not made to words and nonwords, and so there can be no suggestion that this task underestimates priming for nonwords. Second, further evidence that short-term priming reflects the identification (rather than the decision) stage of lexical processing comes from recent work in this laboratory examining short-term priming with auditory, rather than visual, input (McKone \& Dennis, 1998). With spoken words and nonwords, which can be assumed to access phonological rather than orthographic representations, no lag $\times$ lexicality interaction was found, even in the lexical decision task. Together, these two results clearly dissociate the finding of a lag $\times$ lexicality interaction from the use of the lexical decision task. Rather than being task specific, it appears that the interaction reflects a theoretically interesting difference in the types of traces left following (visual) identification of words and nonwords.

\section{Disconfounding Two Components of Lag}

The starting point for the present work was the observation that, although all previous studies of short-lived priming have tracked the repetition benefit as a function of lag, this variable confounds two distinct factors: time delay and number of intervening items. The aim of the present experiments was to disentangle these two factors. Disconfounding time delay and intervening items is relevant to several themes emerging from the literature discussed above, including (1) the role of presentation rate in earlier failures to find short-term priming beyond $\operatorname{Lag} 0$, (2) the mechanism responsible for the lag $\times$ lexicality interaction, and (3) explanations of short-term priming in terms of word identification processes.

The time and intervening items components of lag reflect two theoretical mechanisms that might potentially be responsible for the decay of short-term priming. These mechanisms will be referred to as spontaneous loss and interference. ${ }^{2}$ Spontaneous loss occurs when the trace of the target's first presentation degrades over time alone, without any influence from the processing of other lexical items (i.e., in the absence of new input). As examples, it might be that unit activations representing the prime simply return to their resting levels following the offset of the stimulus, or it might be that noise is present within the system. Interference occurs, in contrast, when the trace of the prime (or perhaps its effect on behavior) is degraded via the processing of other items. For example, a limit on total activation available within the system would force the transfer of activation away from the pattern representing the prime in order to process new stimuli.

In the two experiments reported here, the separation of the influences of time delay and intervening items on the decay of short-term priming was attempted, with the aim of determining whether short-term implicit memory decays via (1) spontaneous loss alone, (2) interference alone, or (3) a combination of both mechanisms. Both experiments used a lexical decision task (slightly modified in the second experiment), with words and pseudowords as targets, but employed different manipulations in order to examine the question of interest. In Experiment 1, time delay and number of intervening items were manipulated in turn, while the other factor was held constant. In Experiment 2 , decay curves for priming were examined over time delays of 2-16 sec, with and without the presence of intervening lexical items - that is, patterns of decay were examined as being due to time alone and as being due to time plus interference. In both experiments, the independent contribution of each component of lag was assessed, and, in Experiment 2, the relative contribution of each mechanism to the overall decay curves for words and nonwords (particularly the lag $\times$ lexicality interaction) was further determined.

\section{EXPERIMENT 1}

In Experiment 1, the number of items intervening between repeats was varied while time delay was held constant, and the time delay between repeats was varied while the number of intervening items was held constant. Each manipulation of time delay or interference took place relative to a reference point - namely, a particular combination of time interval and number of items intervening 
between repeats. For example, one reference point, referred to as the ref $0 i-4 s$ condition, included 0 items and $4 \mathrm{sec}$ between target repeats. Then, in a less-time condition, the time delay was varied (specifically, reduced) in comparison with the reference point, while the number of intervening items was held constant (e.g., a $0 i-2 s$ condition was used for the ref $0 i-4 s$ reference point). In a more-items condition, the number of intervening items was varied (specifically, increased) in comparison with the reference point, while the time delay remained the same (e.g., a $1 i-4 s$ condition was used for the ref $0 i-4 s$ reference point). For a given reference point, then, three decay conditions were defined-namely, the reference, less-time, and more-items conditions.

To examine the effect of time interval and interference for both short-term and long-term priming, three reference points were used. These points were ref $0 i-4 s$, ref $4 i-20 s$, and ref $9 i-40 s$; they were produced by presenting 0,4 , or 9 intervening items between target repeats presented at a rate of one trial every $4 \mathrm{sec}$. (Note that Figure 1 shows priming at Lags 0 through 9, with trials presented at the faster rate of one trial every $2 \mathrm{sec}$.) The relevant less-time and more-items conditions were then produced by presenting $0,1,4,9$, or 19 intervening items at a rate of one trial every $2 \mathrm{sec}$. Presentation rate was blocked, not mixed. It was assumed that priming at the "shortest" reference point ( $r e f 0 i-4 s$ ) would reflect a component that was due to short-term implicit memory (as well as a much smaller contribution from long-lived priming), whereas the "longest" (ref $9 i-40 s$ ) would tap only long-term implicit memory. The "middle" reference point (ref $4 i-20 \mathrm{~s}$ ) was chosen as reflecting the possible boundary of short-term influence.

\section{Method}

Subjects. Twenty-one undergraduate students attending the Australian National University participated in return for course credit.

Design. A repeated measures $3 \times 3 \times 2$ design was used (reference lag with a 4 -sec-per-item presentation rate $\times$ decay condition $\times$ lexical status). The three reference points were 0 -items -4 -sec (ref $0 i-4 s$ ), 4-items-20-sec (ref 4i-20s), and 9-items-40-sec (ref $9 i-40 s$ ). The three decay conditions consisted of a reference point and its corresponding less-time and more-items conditions. Targets of each lexical status (words and nonwords) were tested. The task was lexical decision, with repetition priming (the reaction time advantage on a repeated presentation, in comparison with the initial presentation) as the dependent measure.

To specify the exact manipulation of the independent variables, Table 1 shows the iterns-time combinations used for each set of decay conditions, plus the presentation rate necessary to produce each condition. Condition $9 i-20 s$, which was common to two reference points, was only tested once, in order to restrict the total number of trials and items required. (This restricted the forms of data analysis possible; for example, it was not possible to conduct a three-way analysis of variance (ANOVA) including reference lag, decay condition, and lexical status.)

Materials. As summarized in Table 1, five experimental conditions required a 2 -sec-per-item presentation rate-namely, the $(0 i-2 s, 1 i-4 s, 4 i-10 s, 9 i-20 s$, and $19 i-40 s$ conditions (i.e., the lesstime and more-items decay conditions). However, only three experimental conditions - namely, the $0 i-4 s, 4 i-20 s$, and $9 i-40 s$ conditions (i.c., the reference points)---required a 4 -sec-per-item presentation rate. To avoid any differences between the structure of the blocks
Table 1

Number of Intervening Items and

Time Delay for Each Experimental Condition, Expressed as Items-Time in Experiment 1

\begin{tabular}{clll}
\hline & \multicolumn{3}{c}{ Conditions } \\
\cline { 2 - 4 } & Less-Time & Reference & More-Items \\
\hline Items-time & & & \\
combinations & $0 \mathrm{i}-2 \mathrm{~s}$ & $0 \mathrm{i}-4 \mathrm{~s}$ & $1 \mathrm{i}-4 \mathrm{~s}$ \\
& $4 \mathrm{i}-10 \mathrm{~s}$ & $4 \mathrm{i}-20 \mathrm{~s}$ & $9 \mathrm{i}-20 \mathrm{~s}$ \\
& $9 \mathrm{i}-20 \mathrm{~s}$ & $9 \mathrm{i}-40 \mathrm{~s}$ & $19 \mathrm{i}-40 \mathrm{~s}$ \\
Presentation rate & $2 \mathrm{sec}$ & $4 \mathrm{sec}$ & $2 \mathrm{sec}$ \\
\hline
\end{tabular}

Note $-4 \mathrm{i}-10 \mathrm{~s}$, for example, indicates that four items and $10 \mathrm{sec}$ intervened between repeats. The presentation rate necessary to produce each combination is also shown.

shown at each presentation rate, two dummy conditions were added to the list, to be presented at the slower rate. These conditions were $1 i-8 s$ and $19 i-80 s$; their addition ensured that the total number of trials, the proportion of repeats, and the number of items intervening between repeats were the same across the two presentation rates. To further match the lists to be shown at each presentation rate as far as possible, items for the two dummy conditions were chosen from the same pool as were the critical items.

The addition of the dummy conditions meant that target items were required for a total of 10 word conditions and 10 nonword conditions (although priming was of interest in only 8 of each). For each subject, 18 items were presented per condition, thus requiring a total of 180 target words and 180 target nonwords. The items were the same low-frequency words and pseudowords described in full in Experiment 1 of McKone (1995). The target words were four letters long, single syllable, and had frequency counts of between one and four occurrences per million, according to the Kučera and Francis (1967) counts. Items likely to be completely unfamiliar to the subjects were excluded from the pool. The target nonwords were fourletter, single-syllable pseudowords that obeyed the orthographic and phonological rules of English (e.g., mave). Nonwords were not homophonic to real words.

The trial order was then determined, initially for the list of trials to be presented at the 2 -sec-per-item rate. To manipulate the number of items intervening between repeats while keeping the total number of trials to a minimum, it was necessary to closely overlap the various lag conditions. That is, items that appeared as intervening items for a target in any particular condition were themselves often target items for other conditions. To specify the trial order necessary to achieve this, sequence templates of 45 trials were chosen. Each template contained two occurrences of each of the five item-time conditions appearing in the 2 -sec list. Presentation of these conditions thus took up 40 trials of the 45 -trial template (5 conditions $\times 2$ occurrences of each per template $\times 2$ for words and nonwords $\times 2$ for first and second presentation). The remaining 5 trials contained unrepeated fillers (these matched the targets in most ways but were slightly higher in frequency for the real words). For the full 2-sec list, three different sequence templates were constructed. Each of these was then used three times, allowing the presentation of a total of 18 items per condition. In total, the 2 -sec list contained 405 trials (targets: 5 conditions each seen twice per template $\times 2$ for words and nonwords $\times 2$ presentations $\times 9$ templates; plus fillers: 5 per template $\times 9$ templates).

The trial order for the 4-sec list was determined simply by reversing that of the $2-\mathrm{sec}$ list. This provided an easy way of producing a new order while maintaining the correct number of trials between repeats in the various conditions and was possible because the lag conditions used at the 4-sec-per-item presentation rate were the same as those presented at the faster rate. The 4-sec list again contained 18 presentations of each condition and was 405 trials long in total. The unrepeated fillers differed from those used in the 2-sec list. 
Following the determination of trial order for the 2-sec and 4-sec lists, the target items were assigned to conditions. For word targets, the total pool of 180 items was divided into 10 sets of 18 items. Eight of these sets were cycled through the conditions of interest over eight different versions of each list; this was done to avoid any effects of specific items on priming in particular conditions. Two sets were assigned to the dummy conditions in the same way for all the subjects. This assignment procedure was then repeated for nonword targets.

Procedure. Each subject was tested individually in a $1-\mathrm{h}$ session. Items were presented using PsychLab software on a Macintosh computer, with a new trial beginning at regular intervals, regardless of the time the subject took to respond. Items remained on the screen until the subject responded via one of two buttons on the keyboard, using the preferred hand for a yes (word) decision and the other hand for a no (nonword) decision. The key pressed and the response latency from onset of the item were recorded. The subjects were instructed to respond as quickly as possible, consistent with being correct. No feedback was given regarding accuracy or speed. If the subject had not responded within the prescribed period ( 2 or $4 \mathrm{sec}$ ), the next trial commenced. They were instructed that, should this happen, they were to ignore the item they had missed.

Each of the eight cycled versions of each list was used either two or three times over the 21 subjects. For testing, each list was split into three blocks of 135 trials, so that no repeats were split across blocks. The order of testing each presentation rate was counterbalanced across subjects, with half receiving the three 2 -sec test blocks followed by the three 4-sec test blocks and half receiving the reverse order. With the faster presentation rate, each block took $4.5 \mathrm{~min}$ to complete. With the slower presentation rate, each block lasted $9 \mathrm{~min}$. Short breaks were allowed between blocks, and 25 trials of practice were included before each of the $2-\sec$ and $4-\sec$ lists

\section{Results and Discussion}

Mean error rates for words were $11.5 \%$ for first presentations and $4.8 \%$ for second presentations. Nonword error rates were $4.3 \%$ for first presentations and $4.6 \%$ for second presentations. Reaction times were excluded from analysis if an error was made to either presentation or if the response time was $<300 \mathrm{msec}$ or $>1,200 \mathrm{msec}$. On this basis, $1.3 \%$ of the word trials and $1.2 \%$ of the nonword trials were excluded as outliers.

Baseline decision times. First-presentation decision times are shown in Table 2. These constituted the baseline against which priming was assessed and were found to be approximately $30 \mathrm{msec}$ slower for the three reference conditions (which were presented in the slow presentation rate blocks) than for the other decay conditions (presented in the fast presentation rate blocks). Collapsing across conditions, mean lexical decision times to first presentations were $658 \mathrm{msec}$ for words and $679 \mathrm{msec}$ for nonwords in the 2-sec-per-item blocks but 685 and $711 \mathrm{msec}$, respectively, in the 4-sec-per-item blocks. A two-way ANOVA (presentation rate $\times$ lexical status) on these data revealed that the main effect of presentation rate was significant $\left[F(1,20)=19.0, M S_{\mathrm{e}}=976, p<.001\right]$.

Thus, there were unexpected differences in baseline reaction times across different conditions, with longer baselines observed when the slower presentation rate was used. ${ }^{3}$ This finding creates a potential difficulty in comparing priming levels in the reference conditions with those in the less-time and more-items conditions. It is usual to find larger repetition effects where the baseline reaction times are slower (e.g., compare naming and lexical decision in McKone, 1995, or Monsell, 1985), presumably because there is more "room to improve" on a repeated presentation (see Snodgrass, 1989). In this case, such an effect would imply that priming in the reference conditions would be inflated somewhat, relative to that in the other decay conditions. The priming data were analyzed despite the unequal baselines, as there were good reasons (see below) for believing that the problem did not compromise the overall conclusions to be drawn from the experiment.

Priming data. Figure 2 shows the mean priming effects in each condition, calculated as first minus second presentation reaction times (see Table 2 for mean reaction times). The first issue to be addressed in the priming data was a confirmation of short-term priming in the reference conditions. The black bars in Figure 2 show priming in the reference conditions with zero, four, and nine intervening items. These would be expected to demonstrate short-term priming at ref $0 i-4 s$ and, possibly, also at ref $4 i-20 s$, over and above long-term priming at ref $9 i-40$ s. As can be seen, this general pattern was supported for both words and nonwords, although substantial short-term priming is apparent only at ref $0 i-4 s$.

The presence of short-term priming in the reference conditions was confirmed, first, by one-way ANOVAs and then by follow-up Helmert contrasts (Norusis, 1988) that compare each point on the decay curve to the average of all the later points. The ANOVAs revealed a signifi-

Table 2

Mean Lexical Decision Times (RT, in Milliseconds) and Error Rates (E, in Percentages) at Each Reference Point, for Words and Nonwords in Experiment 1

\begin{tabular}{|c|c|c|c|c|c|c|c|c|c|c|c|c|c|c|c|c|c|c|}
\hline \multirow[b]{3}{*}{ Condition } & \multicolumn{6}{|c|}{ ref $0 \mathrm{i}-4 \mathrm{~s}$} & \multicolumn{6}{|c|}{ ref $4 i-20 s$} & \multicolumn{6}{|c|}{ ref $9 i-40 s$} \\
\hline & \multicolumn{2}{|c|}{$1-t$} & \multicolumn{2}{|c|}{$\mathrm{r}$} & \multicolumn{2}{|c|}{$\mathrm{m}-\mathrm{i}$} & \multicolumn{2}{|c|}{$1-\mathrm{t}$} & \multicolumn{2}{|c|}{$r$} & \multicolumn{2}{|c|}{$\mathrm{m}-\mathrm{i}$} & \multicolumn{2}{|c|}{$1-\mathrm{t}$} & \multicolumn{2}{|c|}{$r$} & \multicolumn{2}{|c|}{$m-i$} \\
\hline & RT & $\mathrm{E}$ & RT & $\mathrm{E}$ & RT & $\mathrm{E}$ & $\mathrm{RT}$ & $\mathrm{E}$ & RT & $E$ & RT & $\mathrm{E}$ & RT & $E$ & RT & E & RT & $\mathrm{E}$ \\
\hline \multicolumn{19}{|l|}{ Words } \\
\hline First presentation & 653 & 10 & 679 & 12 & 657 & 10 & 679 & 11 & 696 & 12 & 655 & 13 & 655 & 13 & 680 & 12 & 646 & 12 \\
\hline Second presentation & 485 & 4 & 533 & 4 & 584 & 5 & 597 & 6 & 609 & 6 & 586 & 6 & 586 & 6 & 616 & 5 & 588 & 3 \\
\hline \multicolumn{19}{|l|}{ Nonwords } \\
\hline First presentation & 677 & 3 & 712 & 3 & 683 & 6 & 671 & 3 & 709 & 3 & 689 & 7 & 689 & 7 & 714 & 2 & 676 & 7 \\
\hline Second presentation & 539 & 1 & 611 & 2 & 642 & 5 & 652 & 4 & 676 & 5 & 666 & 6 & 666 & 6 & 692 & 5 & 672 & 9 \\
\hline
\end{tabular}

Note-Data are shown for the less-time condition (l-t), the reference condition ( $r$ ), and the more-items condition (m-i). 

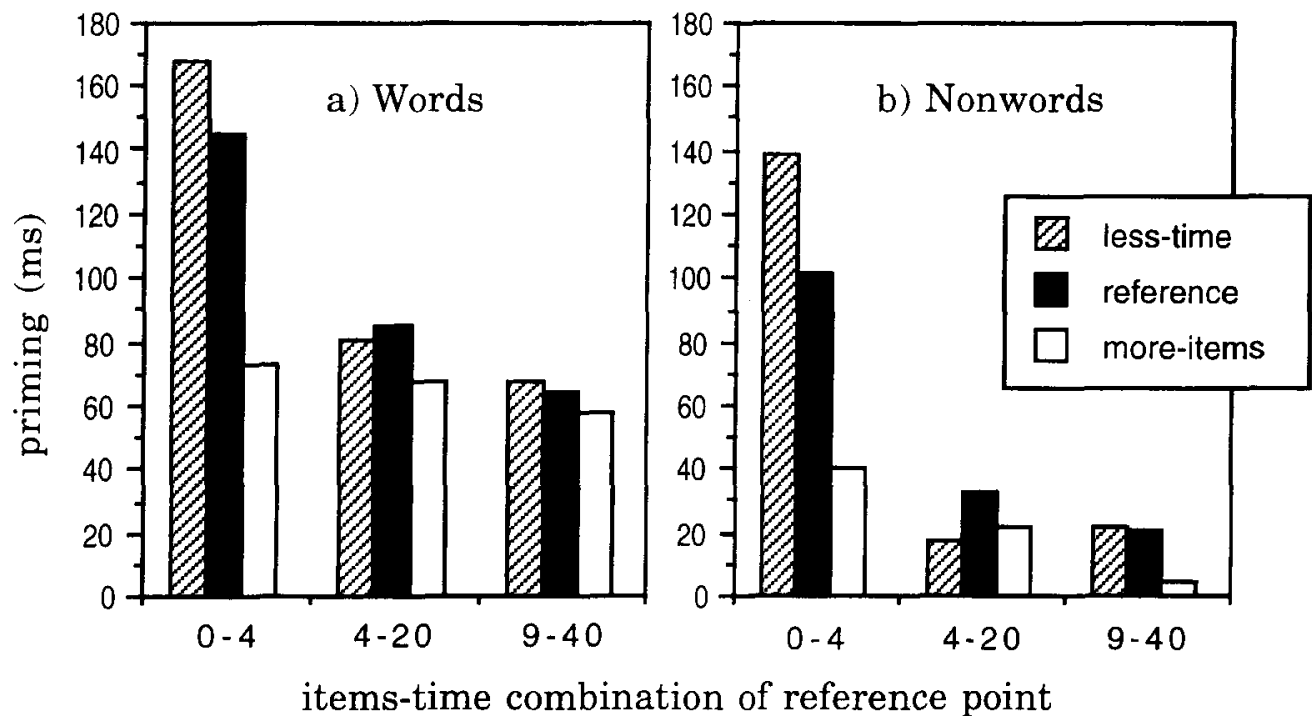

Figure 2. Experiment 1. Priming (in milliseconds) in the less-time, reference, and more-items conditions, at each of three reference points for (a) words and (b) nonwords. The three reference points in each plot (the black bars) correspond to Lags 0,4 , and 9 on a 4 -sec-per-item decay curve. The $x$-axis shows the items-time combination for each of these. See Table 2 for details of the other decay conditions.

cant overall effect of the number of intervening items, both for words $\left[F(2,40)=20.7, M S_{\mathrm{e}}=1,797, p<.001\right]$ and for nonwords $\left[F(2,40)=29.0, M S_{\mathrm{e}}=1,327, p<.001\right]$ Priming with zero intervening items was then found to be significantly greater than priming averaged across the two longer reference conditions, again both for words $[F(1,40)=38.5, p<.001]$ and for nonwords $[F(1,40)=$ $57.1, p<.001]$. The much smaller advantage of the middle reference condition (four intervening items) over the long-term condition (nine intervening items) did not reach significance, either for words $[F(1,40)=3.06, p>.05]$ or for nonwords $(F<1)$. Thus, significant short-term priming in the reference conditions was present at the ref $0 i-4 s$ point but had dissipated by the ref $4 i-20 s$ point.

Thus, short-term priming was found at the shortest reference point, and it was established that the effect decayed with increasing time and/or items across the reference conditions. To assess the reasons for the decay, patterns of priming were examined within the set of decay conditions used for the ref $0 i-4 s$ point. If time alone were responsible for the decay of short-term priming, the following pattern should be observed: less-time $>$ reference $=$ more-items. If interference alone were responsible, the pattern should take the form less-time $=$ reference $>$ more-items. If both factors provide partial contributions to the overall decay, the pattern of priming should be less-time $>$ reference $>$ more-items.

Figure 2 shows that it was the last of these three possibilities that was observed. For both words and nonwords, priming in the ref $0 i-4 s$ condition fell somewhere between that in the less-time condition (maximum priming; see the striped bar in Figure 2) and that in the moreitems condition (minimum priming; see the white bar in Figure 2), indicating contributions of both spontaneous loss and interference to the decay of short-term priming. Statistical confirmation of this pattern was obtained. Oneway ANOVAs comparing the ref $0 i-4 s$ condition with its less-time and more-items conditions found significant overall differences for words $\left[F(2,40)=46.9, M S_{\mathrm{e}}=\right.$ $1,099, p<.001]$ and for nonwords $\left[F(2,40)=28.9, M S_{\mathrm{e}}=\right.$ $1,819, p<.001]$. Follow-up comparisons revealed significantly more priming in the less-time than in the reference condition, for both words $[t(20)=2.74, p<.02]$ and nonwords $[t(20)=2.88, p<.01]$. Thus, priming decayed partly because of time delay between repeats. Priming in the reference condition was also significantly above that in the more-items condition, for both words $[t(20)=6.6$, $p<.001]$ and nonwords $[t(20)=4.73, p<.001]$. Thus, priming also decayed partly because of the presence of intervening items.

One-way ANOVAs were also conducted within each set of decay conditions for the ref $4 i-20 s$ and ref $9 i-40 s$ reference points. No significant differences were found, relative to either reference point, for either words or nonwords (largest $F=2.04$, smallest $p>.1$ ). This indicates no significant decay that is due to either time delay or interference, a finding that is unsurprising, given the evidence, presented above, that a stable long-term priming value had been reached by ref $4 i-20 \mathrm{~s}$. Such a finding does not necessarily imply that long-term priming will not eventually decay through one or both mechanisms but does show that the decay rate of such priming is too slow to be significantly affected by a 10 - or 20 -sec increase in time delay or by a 5 - or 10 -item increase in the amount of interference.

Dealing with unequal baselines. There are three reasons for thinking that baseline differences between the 4and the 2 -sec presentation rates do not compromise the 
validity of the conclusions drawn regarding the decay mechanisms of short-term priming. First, an examination of the long-term conditions (see Figure 2) suggests that baseline differences had, at most, a very small effect on priming. Here, little or no difference between the various decay conditions would be expected theoretically, and only very small differences were observed, despite the baseline differences.

Second, the effects at the short reference point were so large that it is highly unlikely that baseline differences could explain away the effect of either time delay or interference on short-term priming. In Figure 2, priming at the ref $0 i-4 s$ point might well have been somewhat overestimated, relative to its comparison decay conditions, given its longer baseline. Any reasonable adjustment for this, however, would (1) still leave substantially more priming at the reference point than in the moreitems condition (unless it were to be argued that differences in priming of 60-70 msec between these two conditions could be attributed entirely to a baseline difference of only $30 \mathrm{msec}$ ) and (2) only serve to further increase an already significant difference between the less-time condition and the reference point.

Third, expressing priming as a percentage improvement from baseline, rather than as an absolute decrease in reaction time, did not change the results. This procedure would be expected to remove at least some of the influence of initial-presentation reaction times on the repetition benefit. For the ref $0 i-4 s$ point, percentage priming was $25.6 \%$ (less-time condition), $21.3 \%$ (reference condition), and $11.1 \%$ (more-items condition) for words and $20.3 \%$ (less-time condition), $13.8 \%$ (reference condition), and $5.6 \%$ (more-items condition) for nonwords. One-way ANOVAs found significant effects of decay condition for both words $\left[F(2,40)=67.0, M S_{\mathrm{e}}=17.54\right.$, $p<.001]$ and nonwords $\left[F(2,40)=36.1, M S_{\mathrm{e}}=31.15\right.$, $p<.001] . t$ tests then revealed that the less-time versus reference advantage was significant for words $[t(20)=$ $4.32, p<.001]$ and nonwords $[t(20)=3.86, p<.005]$, and the reference versus more-items advantage was also significant for words $[t(20)=7.51, p<.001]$ and nonwords $[t(20)=4.93, p<.001]$. Thus, a relative measure of priming, taking into account baseline differences, replicated the finding that less-time $>$ reference $>$ more-items.

Error data. Table 2 includes error rates in all conditions. These indicate that speed-accuracy tradeoffs were not responsible for producing priming of reaction times or for the particular patterns of priming observed. For the ref $0 i-4 s$ reference point, there was a trend toward error rates on primed trials (i.e., second presentations) being lowest in the less-time condition, slightly higher in the reference condition, and higher again in the more-items condition. This is consistent with the pattern in the reaction time data, which shows the most priming in the lesstime condition and the least in the more-items condition. One-way ANOVAs revealed that this trend was not significant for words $(F<1)$ but was for nonwords $[F(2,40)=$ $\left.7.0, M S_{\mathrm{e}}=0.47, p<.01\right]$. For the longer reference lags, Table 2 shows the patterns of errors to be more random, and no significant differences were found within any set of conditions (largest $F=2.69$, smallest $p=.08$ ).

\section{EXPERIMENT 2}

In the experiments presented in McKone (1995), shortterm priming decayed over lag in a manner that differed sharply for words and nonwords (see Figure 1). Priming for words showed a smooth decay pattern and lasted through approximately three intervening items, whereas priming for nonwords decayed precipitously, being brought down to the long-term value by a single intervening item. Given the evidence from Experiment 1 that time delay and intervening items both contribute something to the decay of short-term priming, the focus in Experiment 2 was on the way in which these two factors combine to produce the lag $\times$ lexicality interaction. Of particular interest was the mechanism underlying the very rapid decay of priming for nonwords. Theoretically, this effect could arise (1) because traces of nonwords are spontaneously lost faster than those of real words, (2) because nonword traces are unusually sensitive to interference, or (3) because nonword traces are weaker in both of these senses. The aim of Experiment 2 was to evaluate these various possibilities.

In Experiment 2, a design similar to those in the earlier lag experiments was used (i.e., a design quite different from that of Experiment 1), but priming was examined as a function of the time delay between repeats, rather than as a function of lag. Time delays of between 2 and $16 \mathrm{sec}$ were employed, with a new intervening trial presented every $2 \mathrm{sec}$ during the delay. The critical manipulation was the nature of the stimulus presented on these intervening trials. In the without-interference conditions, blank placeholders appeared on each intervening trial. Thus, decay under these conditions was used to assess the effects of spontaneous loss over time alone (or at least without direct interference to the state of the lexical processing system). In the with-interference conditions, lexical items (i.e., words or nonwords) were presented every $2 \mathrm{sec}$ between target repeats. These time-plus-interference conditions corresponded to the manipulation of lag employed in McKone (1995), and, thus, the combined effects of interference and spontaneous loss on decay were assessed.

As in Experiment 1, the targets used in Experiment 2 consisted of pseudowords and very low frequency words. The task was a modified version of lexical decision. Subjects responded yes to words, responded no to nonwords, and did not respond at all to blanks, which consisted of a row of eight colons (i.e., :.:.:.:.:). The use of some form of placeholder was required in order to force the subjects to maintain their attention on the screen during long delays between lexical items: The subjects could not predict in advance the nature of any particular trial, and so all required full attention in case a response was required. It was assumed that the blanks would provide no interference to the traces underlying short-term priming for words and nonwords, given that they contained no letter-like or word-like features. 
The time delays employed between repeats were 2, 4, $6,8,10$, and $16 \mathrm{sec}$. In the with-interference conditions, these corresponded exactly to $\operatorname{Lag} 0, \operatorname{Lag} 1, \operatorname{Lag} 2, \operatorname{Lag} 3$, Lag 4, and Lag 7 as shown in Figure 1. Note that, even with interference, only one time delay ( $16 \mathrm{sec}$, or Lag 7) clearly fell outside the region of influence from shortterm priming. Without interference, where the decay of priming might well be slower, it was not certain that even this point would reflect only long-term priming. That is, it is possible that the asymptotic long-term value might not be attained by the 16-sec delay, especially without interference. Unfortunately, this methodological limitation could not be avoided, owing to constraints on the total number of trials. As it was, the testing of six delays with and without interference for words and nonwords, along with the large number of blank trials necessary, required each subject to complete more than 2,700 trials.

Given the direct correspondence between the withinterference conditions of the present experiment and the lag conditions of McKone (1995), a first expectation of Experiment 2 was that the results for these conditions would reproduce the patterns obtained earlier, particularly the lag $\times$ lexicality interaction. That is, it was expected that priming with interference would decay smoothly for words but precipitously for nonwords. A second expectation was that of a replication of the results of Experiment 1. In terms of the present design, an independent effect of time delay would show up as some decay of priming over time alone, whereas an independent effect of interference would show up as faster decay when intervening lexical items were added.

The relative contributions of time delay and interference to producing the lag $\times$ lexicality interaction were then assessed as follows. If the interaction arises primarily because nonword traces undergo faster spontaneous loss, the without-interference curve for nonwords should decay noticeably faster than that for words and possibly even show priming to drop precipitously. If the interaction arises primarily because nonword traces are more sensitive to interference, word and nonword decay patterns should take the same general form over time alone, with the addition of intervening items providing the

Table 3

Number of Intervening Lexical Items and Time for Each Experimental Condition, Expressed as Items-Time in Experiment 2

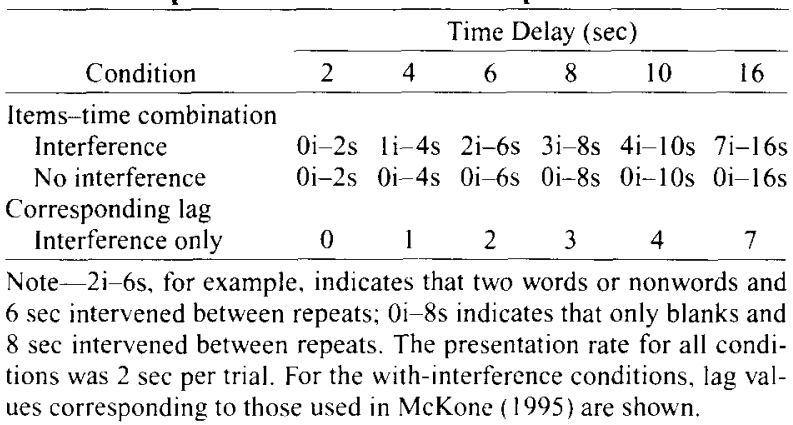

critical factor that produces the sudden drop in nonword priming.

\section{Method}

Subjects. Nineteen undergraduate students participated for course credit, and a further 5 members of the ANU community volunteered for the experiment, giving 24 subjects in all.

Design. Three variables were manipulated within subjects-namely, lexical status of targets (word or nonword), time between repeats of an item $(2,4,6,8,10$, or $16 \mathrm{sec}$, plus an across-session condition), and the nature of the stimuli presented in the intervening period (all blanks or all four-letter strings). Details of the 12 items-time conditions used are given in Table 3. These were repeated for word and nonword targets. The 0 -items-2-sec conditions were considered to be the starting point for decay, both with and without interference. Priming in these conditions was measured only once for targets of each lexical status. Reaction times in a modified lexical decision task were recorded, and priming was calculated as the difference between response times to first and second presentations.

Materials. Targets were 204 low-frequency words and 204 pseudowords, which were a superset of the pools used in Experiment 1 . They were selected on the same basis as that used previously, except that the (informal) criteria for rejecting some real words as being relatively unfamiliar were less strict. Thus, it might be expected that the error rate to words would be higher than that in Experiment 1, but this disadvantage was offset by the advantage of maintaining the same frequency range as that used in the original McKone (1995) experiments. In addition to the targets, 207 filler items of each lexical status were required. Fillers were similar in construction to targets, except that the words included some quite unfamiliar very low frequency words (e.g., gilt), plus items from the frequency range of 5-8 counts per million.

As shown in detail in Table 3,11 critical conditions were tested within sessions, for each lexical status. In addition, 7 dummy conditions were included, which served quite a different function from those used in Experiment 1 . The dummy conditions presented repeated items with a mixture of blanks and letter strings as intervening items and were used to prevent subjects from learning that every series of blanks was followed by a repetition of the last nonblank string (as was the case for the critical conditions $0 i-2 s$ through $0 i-16 s$ ). The exact set of dummy conditions used included: $1 i-6 s, 1 i-8 s, 1 i-10 s$, $1 i-16 s, 2 i-8 s, 2 i-10 s$, and $2 i-16 s$, for each lexical status.

To manipulate the delay between repeats, eight 153 -trial sequence templates were chosen. Each template contained one occurrence of each of the 11 within-session critical conditions and one occurrence of each of the 7 dummy conditions, for both words and nonwords. In addition, 73 blanks and eight unrepeated fillers were included per template. To construct the trial order for the complete list, seven sequence templates were used twice in the complete list, and one three times. This allowed 17 items per condition to be presented and produced a total of 2,601 trials.

The full list was too long to be presented in a single session, and so it was split to be presented in two sessions. Given this necessity, the opportunity was taken to examine long-term priming effects over delays of up to a week, by adding a further sequence of trials to the end of the first-session list and repeating these at the beginning of the second-session list. ${ }^{4}$ Again, 17 items per condition were tested in the across-session conditions. Each test sequence contained 67 trials, which included 17 critical words, 17 critical nonwords, 21 blanks, and six repeated filler items. The complete list was thus 2,735 trials in length $(2,601+67+67)$.

To avoid item-specific effects on priming patterns, each pool of 204 target words or nonwords was broken up into 12 sets of 17 items, corresponding to the 12 critical conditions. Twelve versions of the complete list were then produced, with the sets of target items cycled through the conditions of interest across the different ver- 
sions. Filler items were assigned to the dummy conditions and to unrepeated trials, and these assignments were the same for all versions of the list.

Procedure. Trials were presented at a rate of one every $2 \mathrm{sec}$. The subjects were required to perform a variant of the lexical decision task, such that a yes response with the preferred hand was required to a real word, a no response with the other hand to a nonword, and no response at all to a blank. Blanks (........) took up the same screen width as a four-letter word or nonword. Note that, as the subjects could not predict the nature of the next trial, they were forced to continue paying attention to the screen, even during a string of blanks. Word and nonword items remained on the screen until the subject responded, and blanks always remained for $1.4 \mathrm{sec}$.

The subjects were tested individually in two $1-\mathrm{h}$ sessions. Two subjects were assigned to each of the 12 versions of the full list. The complete list for a session was broken into five blocks for presentation, with the longest blocks each taking 9 min to complete. Repeats were not split across blocks (with the exception of the acrosssessions condition). Practice sets of 45 and 29 trials preceded the first and second sessions, respectively. The time between sessions was not controlled, but varied between $15 \mathrm{~min}$ and $166 \mathrm{~h}$. All other aspects of the procedure were the same as those for Experiment 1.

\section{Results and Discussion}

Average error rates across the conditions of interest were $8.0 \%$ for words and $4.7 \%$ for nonwords. Using a lower cutoff of $300 \mathrm{msec}$ and an upper cutoff of $1,200 \mathrm{msec}$, $0.8 \%$ of the word trials and $1.0 \%$ of the nonword trials in these conditions were excluded as outliers. Mean reaction times to first presentations were $675 \mathrm{msec}$ for words and $708 \mathrm{msec}$ for nonwords.

Figure 3 shows priming for words and nonwords as a function of time delay between repeats, where intervening items were blanks (i.e., without interference) or fourletter strings (i.e., with interference). Table 4 includes the first and second presentation means for all conditions. In the with-interference conditions (the dotted lines in Figure 3), short-term priming for words decayed smoothly over the first few trials, whereas short-term priming for nonwords dropped precipitously to the long-term value with a single intervening item. This pattern is similar to that reported in McKone (1995). In contrast, data from the without-interference conditions (the solid lines in Figure 3 ) revealed a slower decay of priming, with priming for both words and nonwords demonstrating smooth decay.

Statistical analysis of these data was limited by the fact that the $0 i-2 s$ conditions were measured only once for words and once for nonwords. Therefore, it was not possible, for example, to conduct a three-way ANOVA (time delay $X$ lexicality $X$ interference condition) as the starting point of analysis. Instead, analyses are presented that addressed the three questions of primary interest: (1) the degree to which the with-interference decay curves replicate those I have reported earlier; (2) the form of decay for nonwords over time alone and with time-plus-interference; and (3) the form of decay for words over time alone and with time-plus-interference.

A replication of the effects of lag. As noted above, the with-interference conditions correspond to the Lag 0 , $1,2,3$, and 4 conditions used in McKone (1995) and to the equivalent of Lag 7. Therefore, short-term priming

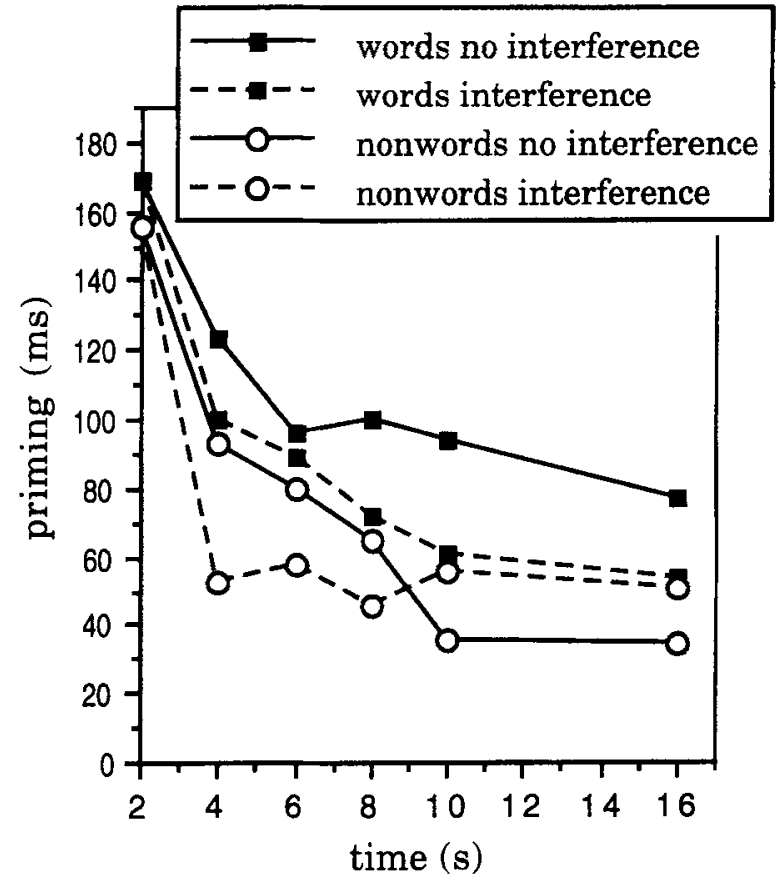

Figure 3. Experiment 2. Priming (in milliseconds) for word and nonword targets as a function of time (in seconds) between repeats, with and without interference. In the interference conditions, lexical items intervened every 2 sec between repeats. In the no-interference conditions, these were replaced with blank placemarkers.

for words with interference should decay smoothly over a number of intervening items, whereas short-term priming for nonwords should decay precipitously to or below the long-term value (see Figure 1). A pattern consistent with these general expectations is apparent in Figure 3 and was confirmed by statistical analyses. A two-way ANOVA (time delay $\times$ lexicality) revealed significant main effects of both time delay $\left[F(1,115)=49.9, M S_{\mathrm{e}}=\right.$ $1,642, p<.001]$ and target lexicality $[F(1,23)=14.9$, $\left.M S_{\mathrm{e}}=2,159, p<.01\right]$ and a significant interaction between the two $\left[F(5,115)=2.64, M S_{\mathrm{e}}=1,381, p<.03\right]$.

Decay patterns for words and nonwords were then examined separately, using Helmert contrasts to compare the priming at each lag with the average priming across all longer lags. The results of these analyses are presented in Table 5. For the with-interference conditions, it can be seen that priming for words remained significantly above that averaged over longer delays at 2,4 , and $6 \mathrm{sec}$ (i.e., Lags 0,1 , and 2), with some hint of a short-term effect remaining at $8 \mathrm{sec}(\operatorname{Lag} 3)$. For nonwords, however, priming was above the long-term value only at Lag 0 .

Decay with and without interference for nonwords. Analyses of the effects of interference were more straightforward for the nonword data than for the word data, and so these are presented first. A $5 \times 2$ ANOVA was conducted on the nonword data (the open circles in Figure 3), which analyzed time delays of $4,6,8,10$, and $16 \mathrm{sec}$ for the with- and without-interference conditions. Note that 
Table 4

\begin{tabular}{|c|c|c|c|c|c|c|c|c|c|c|c|c|}
\hline \multirow{3}{*}{$\begin{array}{l}\text { Lexicality and Interference } \\
\text { Condition }\end{array}$} & \multicolumn{12}{|c|}{ Time delay } \\
\hline & \multicolumn{2}{|l|}{2} & \multicolumn{2}{|l|}{4} & \multicolumn{2}{|l|}{6} & \multicolumn{2}{|c|}{8} & \multicolumn{2}{|c|}{10} & \multicolumn{2}{|c|}{16} \\
\hline & RT & E & $\mathrm{RT}$ & $\mathrm{E}$ & RT & $\mathrm{E}$ & RT & $\mathrm{E}$ & RT & $\mathrm{E}$ & RT & $\mathrm{E}$ \\
\hline \multicolumn{13}{|l|}{ Words no interference } \\
\hline First presentation & 678 & 13 & 681 & 13 & 671 & 10 & 687 & 10 & 684 & 9 & 666 & 13 \\
\hline Second presentation & 509 & 4 & 558 & 3 & 574 & 6 & 586 & 5 & 588 & 5 & 589 & 5 \\
\hline \multicolumn{13}{|l|}{ Words interference } \\
\hline First presentation & & & 662 & 9 & 669 & 9 & 679 & 10 & 683 & 13 & 670 & 10 \\
\hline Second presentation & & & 561 & 5 & 580 & 8 & 606 & 5 & 622 & 7 & 616 & 5 \\
\hline \multicolumn{13}{|l|}{ Nonwords no interference } \\
\hline First presentation & 724 & 5 & 713 & 5 & 713 & 7 & 709 & 6 & 692 & 5 & 697 & 5 \\
\hline Second presentation & 568 & 1 & 620 & 4 & 633 & 5 & 644 & 5 & 656 & 4 & 662 & 4 \\
\hline \multicolumn{13}{|l|}{ Nonwords interference } \\
\hline First presentation & & & 691 & 4 & 715 & 4 & 703 & 5 & 719 & 7 & 714 & 6 \\
\hline Second presentation & & & 638 & 2 & 657 & 6 & 657 & 4 & 662 & 6 & 663 & 4 \\
\hline
\end{tabular}

Note-The 2-sec delay was presented without any intervening trials, and so data from this delay have been included with the no interference conditions.

the 2-sec delay point was theoretically the starting point for both decay curves but could not be included in the initial ANOVA because only one estimate of its value was obtained. The ANOVA revealed a main effect of time delay $\left[F(4,92)=6.5, M S_{\mathrm{e}}=1,304, p<.001\right]$, no main effect of interference $(F \approx 1)$, and an interaction between interference and time $\left[F(4,92)=3.8, M S_{\mathrm{e}}=2,155, p<\right.$ .01 ]. It is apparent from Figure 3 that the interaction took the form of a smooth decay of short-term priming over time alone, in contrast to the sharp decay when interference was present. Helmert contrasts presented in Table 5 confirm that decay was smooth for nonword targets in the absence of interference: Priming was significantly above later values at delays of $2,4,6$, and $8 \mathrm{sec}$.

One other feature of the nonword data deserves mention-namely, a suggestion that the decay curve without interference reached a lower long-term priming value than that with interference. Such a result would be highly counterintuitive. However, the reversed effect of interference on long-term priming was small and far from significant. This was demonstrated by a lack of any main effect of interference in a $2 \times 2$ ANOVA including only the 10- and 16-sec time delays $\left[F(1,23)=2.18, M S_{\mathrm{e}}=\right.$ $3,662, p>.1]$.

For nonwords, then, short-term priming decayed smoothly over time alone, enduring for approximately $10 \mathrm{sec}$. When interference was added, short-term priming decayed completely (i.e., the long-term value was attained) with a single intervening item. Thus, although both time and interference contributed to the decay of short-term priming for nonwords, interference appears to be the critical factor in producing the precipitous decay pattern reported in McKone (1995).

Decay with and without interference for words. A $5 \times 2$ ANOVA (time delay $\times$ interference condition) was conducted on the priming data for words (the filled squares in Figure 3), including only time delays of $4 \mathrm{sec}$ or greater. It revealed that priming was, on average, significantly re- duced when the time delay was increased $[F(4,92)=8.0$, $\left.M S_{\mathrm{e}}=1,804, p<.001\right]$ and significantly reduced when interfering items were added $\left[F(1,23)=6.8, M S_{\mathrm{e}}=4,593\right.$, $p<.02]$. There was no significant interaction between time delay and interference condition $(F<1)$, which suggests that priming (from $4 \mathrm{sec}$ onward) decayed in a similar fashion with and without interference. Helmert contrasts presented in Table 5 confirm this similarity (these contrasts allow analysis of the pattern of decay that includes the 2 -sec point): For word targets, priming decayed smoothly over the first 6 or so sec, both with and without interference.

The lack of any interaction between time delay and interference condition might be seen to suggest (in conflict with the results of Experiment 1) that the short-term component of priming for words was not at all influenced by

Table 5

Results of Helmert Contrasts Between Priming at Each Time and Priming Averaged Across All Subsequent Times in Experiment 2

\begin{tabular}{lccccc}
\hline & \multicolumn{5}{c}{ Time Delay (sec) } \\
\cline { 2 - 6 } & 2 & 4 & 6 & 8 & 10 \\
\hline $\begin{array}{l}\text { Words no interference } \\
\quad \text { Contrast }\end{array}$ & 71 & 31 & 5 & 15 & 18 \\
$F$ & $58.0 \dagger$ & $10.7 \dagger$ & $<1$ & 1.93 & 2.18 \\
Words interference & & & & & \\
$\quad$ Contrast & 94 & 32 & 27 & 14 & 7 \\
$F$ & $124 \dagger$ & $13.6 \dagger$ & $9.01 \dagger$ & 2.29 & $<1$ \\
Nonwords no interference & & & & & \\
$\quad$ Contrast & 94 & 39 & 35 & 29 & 1 \\
$\quad F$ & $92.7 \dagger$ & $15.2 \dagger$ & $11.6 \dagger$ & $7.11 \dagger$ & $<1$ \\
Nonwords interference & & & & & \\
$\quad \begin{array}{l}\text { Contrast } \\
F\end{array}$ & 103 & 0 & 7 & -8 & 5 \\
\end{tabular}

Note - Data shown include the value of the contrast (in milliseconds), and the corresponding $F$ value. For words no interference, $M S_{\mathrm{c}}=$ 1,746; for words interference, $M S_{\mathrm{e}}=1,428$; for nonwords no interference, $M S_{\mathrm{e}}=1,912$; for nonwords interference, $M S_{\mathrm{e}}=1,595 ; d f=$ $(1,115)$ for all comparisons. ${ }^{*} p<.05 . \quad{ }^{+} p<.01$. 
interference; instead, the main effect of interference might reflect a lowering of the long-term priming component (this would reduce priming by a constant amount at all delays that include at least one interfering item). This interpretation, however, rests on the assumption that priming has stabilized at its long-term value by the longest delay employed in the present experiment $(16 \mathrm{sec})$. The data do not clearly support this assumption, particularly without interference. In Figure 3, words without interference (solid curve with filled squares) show some decay after $6 \mathrm{sec}$ (even though the Helmert contrasts indicated that priming at $4 \mathrm{sec}$ was the last point to remain significantly above the average of all later points), and a trend analysis of priming across delays of 6-16 sec found a linear component of decay that approached significance $\left[F(1,23)=3.63, M S_{\mathrm{e}}=1,809, p=.069\right]$. In addition, priming at these delays remained noticeably higher without interference than with interference. If, as must logically be the case, the with- and without-interference curves eventually rejoin each other at longer time delays, the present results would be consistent with an effect of interference on short-term, rather than long-term, priming for words. (Note that practical constraints did not allow additional delays longer than $16 \mathrm{sec}$ to be tested.)

Overall, the word data showed decay of priming over time alone and a further reduction in priming at short delays when interference was introduced (although the conclusion that interference specifically affected the shortterm priming component requires that the with-and without-interference curves eventually rejoin at longer time delays). Given these findings, it can be concluded that both factors contributed to the decay patterns reported in McKone (1995) as a function of lag. In addition, it is clear that short-term priming for words is far less sensitive to interference than is short-term priming for nonwords. The key finding of Experiment 2, therefore, is a clarification of the origin of the lag $\times$ lexicality interaction: This has been shown to arise because nonword traces demonstrate a striking sensitivity to interference, in comparison with word traces.

Error data. Mean error rates to first presentations, across the 2- to 16 -sec delays, were $10.7 \%$ for words and $5.3 \%$ for nonwords. On second presentations, error rates decreased to $5.3 \%$ for words and $4.0 \%$ for nonwords, demonstrating that priming was again manifested in both faster reaction times and fewer errors to repeated targets. With interference, a two-way ANOVA (time delay $\times$ lexicality) was conducted on the second-presentation error rates shown in Table 4. This found a main effect of lexicality $\left[F(1,23)=6.31, M S_{\mathrm{e}}=1.27, p<.02\right]$, with words still showing more errors than nonwords, and a main effect of time delay $\left[F(5,115)=4.97, M S_{\mathrm{e}}=0.78, p<\right.$ $.001]$, such that more priming occurred at shorter delays. There was no time delay $\times$ lexicality interaction $(F<1)$. When the effects of removing interference were then examined for word and nonword targets, two-way ANOVAs (time delay $X$ interference condition) conducted at delays of $4 \mathrm{sec}$ and longer found no significant influences of either delay or interference on second-presentation error rates (largest $F=2.08$, smallest $p>.1$ ). In general, then, error rates to primed targets either were not significantly affected by the factors that influenced reaction times, or demonstrated priming effects in keeping with those apparent in the reaction time priming data.

\section{GENERAL DISCUSSION}

\section{Summary of Results}

One outcome of the present work was a replication of the key features of the lag $\times$ lexicality interaction initially reported in McKone (1995). When the original lag conditions were recreated in the with-interference conditions of Experiment 2, short-term priming showed smooth decay over a few intervening items for words but precipitous decay with a single intervening item for nonwords (compare the dotted curves of Figure 3 with Figure 1). This replication is theoretically uninteresting but valuable, because my original experiments all used the same trial order (where trial order refers to the order of word or nonword status, not to the order of specific items, which were cycled through conditions across different versions of the list). The present Experiment 2 employed newly chosen sequences of trials to manipulate lag but still replicated the lag $\times$ lexicality interaction. ${ }^{5}$

The main contribution of the present experiments was to disentangle the contributions of time delay and intervening items to the overall effect of lag. Each experiment showed that short-term priming decays partially through spontaneous trace loss and partially through the effects of interference. In Experiment 1, manipulating time delay while holding number of intervening items constant affected priming, as did manipulating number of intervening items while holding time delay constant. In Experiment 2, priming was shown to decay as a function of time delay, even when no (lexical) interference occurred, but also to decay faster when intervening items were added.

The results further showed how time and interference combine to produce the lag $\times$ lexicality interaction. This interaction was one of the most interesting findings reported in McKone (1995), in that it indicates that the memory traces underlying short-term priming for nonwords are in some way different from those underlying priming for words. The present results demonstrate that word and nonword traces differ most obviously in their sensitivity to interference. The decay curves found in Experiment 2 showed that, in the absence of interference, priming for nonwords decayed in a smooth manner similar to priming for words (although the rate of spontaneous decay for nonwords was perhaps slightly faster), whereas the striking pattern of precipitous decay for nonwords occurred only when interference was added.

Before theoretical interpretations of the results are considered, two brief comparisons with previous literature can be made. First, a number of studies prior to McKone (1995) failed to find short-term priming beyond Lag 0. The present finding that time delay is one of the factors contributing to the decay of short-term priming provides 
direct support for the suggestion that some such failures might be attributable to the slow presentation rates used in these studies (particularly Ratcliff et al., 1985, and Scarborough et al., 1977).

Second, a dip in nonword priming reported in McKone (1995) was not replicated here (see Experiment 2). Specifically, the findings of McKone suggested that nonword priming dipped slightly (perhaps $10 \mathrm{msec}$ ) below the longterm value somewhere between Lags 1 and 5, before returning to the stable long-term value by Lag 9 . This pattern was variable and not significant in any one experiment but was suggested in each of three priming experiments and reached significance when the data from all three were combined. Although the present results replicated the general features of the lag $\times$ lexicality interaction (i.e., nonword priming decayed precipitously with a single intervening item), there was no hint of any dip. The failure to replicate the dip is important, because I went to some length in McKone to discuss the theoretical implications of this supposed effect, whereas the present results suggest that there was probably nothing to explain. It seems likely that the small dip obtained previously was an artifact of trial order, given that (1) the three relevant experiments in McKone all used the same trial order, (2) the present Experiment 2 used a different trial order and found no dip, and (3) more recent work in this laboratory (McKone \& Dennis, 1998) used a different randomly chosen trial order for every subject and also found no dip (the basic form of precipitous decay for nonwords and smooth decay for words was, however, replicated again).

\section{Short-Term Implicit Memory and Lexical Processing}

The present results indicate that the lag $\times$ lexicality interaction arises because nonword traces are weaker, in the sense that they are written over more easily by subsequent items. If it is accepted that the locus of the shortterm priming effect is the word recognition system (particularly, the orthographic lexicon for written stimuli), it might be useful to consider a concrete illustration of how the patterns of priming might arise in terms of word recognition processes, if only to provide a starting point for more detailed modeling in the future.

The first question is how priming arises at all, for words and, more interestingly, for nonwords. For demonstration purposes, assume that a parallel distributed processing system provides a suitable model of the word recognition system (see, e.g., Seidenberg \& McClelland, 1989). Here, lexical access corresponds to the pattern of activation over the hidden units falling into a particular pattern. For a word target, the pattern to which the system stabilizes will be close to the stored pattern representing that word. For a nonword target, the pattern to which the system stabilizes will be far from that representing any word. (Some measure of distance from familiar representations can then be used to support a lexical decision, and the flow-on of activation from the hidden units to a set of phonological units can be used to support a nam- ing response.) Within such a system, priming during lexical access would correspond to the hidden units stabilizing to their final activations more rapidly on repeated presentation (i.e., the stimulus is resolved faster). Potential mechanisms by which this might occur include transient modification of unit activations, unit thresholds, or connection weights. Any of these mechanisms that allowed priming for real words would also produce priming for pseudowords (as pseudowords activate stable hidden unit patterns in the same way that words do; see Seidenberg \& McClelland, 1989), perhaps by moving the starting point for stimulus resolution closer to the final activation values, or perhaps by increasing the rate of stabilization to those values. Whatever the exact mechanism, the result should be that fewer processing cycles are required to reach the stable pattern and resolve the stimulus, thus speeding lexical access for both words and nonwords. (Of course, in the subsequent decision phase of a lexical decision task, it may be more difficult to say that a nonword is not a real word than it was on the first presentation.)

The second question is, then, how effects of time delay and interference might be produced. The finding of smooth decay in the absence of interference can be easily explained by making the standard assumption that activations (or thresholds, or connection weights) gradually return to their resting levels following the offset of the stimulus (see, e.g., Morton, 1969). Interference could, then, be seen as an additional process in which each new stimulus partially overwrites the modifications within the network that were made in favor of the previous item. For example, if some limit were to be placed on the total unit activation or total weight change allowed within the system, the processing of a new stimulus would necessarily involve transferring some of this limited resource to the new item, thus moving the system to a state less favorable for the processing of the original prime.

The third question is why the effects of interference are so much more severe for nonwords than for words. Without simulation, answers to this question are highly speculative, but at least two general mechanisms might be outlined. One method requires the assumption of localized whole-word units, tacked onto (or perhaps developing out of) a system of distributed representations coding generalized orthographic knowledge (see, e.g., Murre, 1992). Under this scheme, first presentations of real words modify both whole-word and sublexical/distributed representations, whereas first presentations of nonwords modify the latter only (nonwords, by definition, do not have a representation as a familiar whole). For repeats at Lag 0 , where no interfering items have disturbed the state of the system, priming should then occur for both words and nonwords. However, when other items appear between target repeats (i.e., from Lag 1 onward), initial modifications of sublexical or distributed representations are likely to be overwritten, given that these will participate in the processing of many different words and nonwords. Shortterm priming for nonwords will be catastrophically affected by even a single intervening item, because prim- 
ing for nonwords depends on these representations only. Priming for words, in contrast, will survive interference more easily, because part of such priming arises from a unit specific to the target word that should be relatively immune to the processing of successive stimuli.

An alternative method of producing the lag $\times$ lexicality interaction, which does not require an appeal to localized as well as distributed representations, is based on a proposal by Rueckl (1990; also see Rueckl \& Olds, 1993) regarding the influence of semantic feedback on orthographic priming. Rueckl proposes a purely distributed system in which both words and pseudowords produce strong activations at the level of orthographic representations. Words and pseudowords differ, however, in the degree to which this orthographic activation then produces stable activations at the semantic level. For a word, flow of activation from the orthographic processing module to a semantic processing module will produce a pattern of activation at the semantic level that quickly stabilizes to a familiar state representing the meaning of that word. For a pseudoword, however, weaker overall activation and/or less stable patterns would be expected, given the highly inconsistent mapping between word form and word meaning in English. This, then, has implications for the ability of priming to survive interference: Real words might survive longer because feedback from the semantic level is available to maintain the orthographic pattern of a word active even through interference from other items, whereas nonwords are disrupted more easily because little top-down support is available to assist with maintenance of pseudoword activations.

\section{Conclusions}

The present results show that both time delay and interference contribute to the decay of short-term priming for lexical stimuli and that priming for nonwords is much more sensitive to interference than is priming for words. Although the exact mechanisms by which such a pattern might be produced remain unknown, one general implication of the results is that the word recognition system can maintain multiple, fully identified real words active at once (i.e., visual word recognition operates within a window including a few seconds and/or a few items). For visually presented nonwords, in contrast, the catastrophic effects of interference would appear to limit the capacity of short-term implicit memory to only one item.

\section{REFERENCES}

ANDREWS, S. (1992). Frequency and neighborhood effects of lexical access: Lexical similarity or orthographic redundancy? Journal of Experimental Psychology: Learning, Memory, \& Cognition, 18, 234-254.

BENTIN, S., \& Moscovitch, M. (1988). The time course of repetition effects for words and unfamiliar faces. Journal of Experimental Psychology: General, 117, 148-160.

BowERS, J. S. (1994). Does implicit memory extend to legal and illegal nonwords? Journal of Experimental Psychology: Learning, Memory, \& Cognition, 20, 534-549.

DoRFMan, J. (1994). Sublexical components in implicit memory for novel words. Journal of Experimental Psychology: Learning, Memory \& Cognition, 20, í108-1125.
Feustel, T. C., Shiffrin, R. M., \& Salasoo, A. (1983). Episodic and lexical contributions to the repetition effect in word identification. Journal of Experimental Psychology: General, 112, 309-346.

GRAF, P., \& SCHACTER, D. L. (1985). Implicit and explicit memory for new associations in normal and amnesic subjects. Journal of Experimental Psychology: Learning, Memory, \& Cognition, 11, 501-518.

Hintzman, D. L., \& Caulton, D. A. (1995, November). Retrieval dynamics of recognition memory and lexical decision. Paper presented at the 36th annual meeting of the Psychonomic Society, Los Angeles.

KERSTEEN-TUCKER, Z. (1991). Long-term repetition priming with symmetrical polygons and words. Memory \& Cognition, 19, 37-43.

KIRSNER, K., \& SMITH, M. C. (1974). Modality effects in word identification. Memory \& Cognition, 2, 637-640.

KUČERA, M., \& FrANCIS, W. (1967). Computational analysis of present day American English. Providence, RI: Brown University Press.

MaljKovic, V., \& NaKaYama, K. (1994). Priming of pop-out: I. Role of features. Memory \& Cognition, 22, 657-672.

MCClelland, J. L., \& RumelharT, D. E. (1981). An interactive activation model of context effects in letter perception: Part 1. An account of basic findings. Psychological Review, 88, 375-407.

MCKone, E. (1995). Short term implicit memory for words and nonwords. Journal of Experimental Psychology: Learning, Memory, \& Cognition, 21, 1108-1126.

McKone, E., \& DENNIS, C. (1998). Short-term implicit memory: Auditory and cross-modality priming. Manuscript submitted for publication.

McKone, E., \& TRYNes, K. (in press). Acquisition of episode-specific traces in short-term implicit memory: Priming for illegal nonwords and new associations. Memory \& Cognition.

Miller, G. A. (1956). The magical number seven, plus or minus two: Some limits on our capacity to process information. Psychological Review, 63, 81-97.

MONSELL, S. (1985). Repetition and the lexicon. In A. W. Ellis (Ed.), Progress in the psychology of language (pp. 147-195). London: Erlbaum.

MORTON, J. (1969). Interaction of information in word recognition. Psychological Review, 76, 165-178.

MURRE, J. M. J. (1992). Learning and categorization in modular neural networks. Hertfordshire, U.K.: Harvester Wheatsheaf.

NoRUSIS, M. J. (1988). SPSS-X advanced statistics guide (2nd ed.). Chicago: SPSS.

Ratcliff, R., Hockley, W., \& McKoon, G. (1985). Components of activation: Repetition and priming effects in lexical decision and recognition. Journal of Experimental Psychology: General, 114, 435-450.

RoEdiger, H. L., III, \& MCDERMot T, K. B. (1993). Implicit memory in normal human subjects. In F. Boller \& J. Grafman (Eds.), Handbook of neuropsychology (Vol. 8, pp. 63-131). Amsterdam: Elsevier.

RUECKL, J. G. (1990). Similarity effects in word and pseudoword repetition priming. Journal of Experimental Psychology: Learning. Memory, \& Cognition, 16, 374-391.

RueCKL, J. G., \& OlDS, E. M. (1993). When pseudowords acquire meaning: Effect of semantic associations on pseudoword repetition priming. Journal of Experimental Psychology: Learning, Memory, \& Cognition, 19, 515-527.

Scarborough, D. L., Cortese, C., \& Scarborough, H. S. (1977) Frequency and repetition effects in lexical memory. Journal of Experimental Psychology: Human Perception \& Performance, 3, 1-17.

SCHACTER, D. L. (1987). Implicit memory: History and current status. Journal of Experimental Psychology: Learning, Memory, \& Cognition, 13, 501-518.

SeidenberG, M. S., \& MCClelland, J. L. (1989). A distributed, developmental model of word recognition and naming. Psychological Review, 96, 523-568.

SNODGRASS, J. G. (1989). Sources of learning in the picture fragment completion task. In S. Lewandowsky, J. C. Dunn, \& K. Kirsner (Eds.), Implicit memory: Theoretical issues (pp. 259-282). Hillsdale, NJ: Erlbaum.

TAFT, M. (1991). Reading and the mental lexicon. Hove, U.K.: Erlbaum. TENPENNy, P. L. (1995). Abstractionist versus episodic theories of repetition priming and word identification. Psychonomic Bulletin \& Review, 2, 339-363.

Waugh, N. C., \& Norman, D. A. (1965). Primary memory. Psychological Review, 72, 89-104. 


\section{NOTES}

1. I am not claiming here that all short-term implicit memory should be explained in terms of the lexical processing system. The effect reported by Maljkovic and Nakayama (1994) is clearly not lexical in nature. Further, recent work in this laboratory (McKone \& Trynes, in press) demonstrates that priming even for words and nonwords does not always rely on activation of the word recognition system: In that study, short-term priming was observed, even for highly illegal nonsense strings, when a letter-matching task was used, as opposed to lexical decision or naming.

2. The terminology chosen here deserves some clarification. In the literature on short-term explicit memory (e.g., Waugh \& Norman, 1965), decav has been used to refer to what is here called spontaneous loss, and the term forgetting has been used for what is here referred to as decay. In contrast, I have employed a common convention of using decay simply to refer to an observed reduction in the dependent variable of interest (i.e., to refer to the shape of the empirical decay curve), rather than to any particular underlying mechanism. I have avoided the use of forgetting, because of its unwanted overtones of a loss of specifically explicit memory.

3. The slower decision times with the 4-sec presentation rate might have arisen from drifts in subjects' attention during the more than $3 \mathrm{sec}$ of waiting for the next item. Subjects reported that they found the slow rate blocks particularly boring, and any resultant attention drifts would require reorientation to a new trial before a response could be made. This would be expected to slow overall decision times in the 4-sec blocks, relative to the faster presentation rate.

4. The time between sessions was not controlled (range $=15 \mathrm{~min}$ to $166 \mathrm{~h}$, mean $=46.5 \mathrm{~h}$ ), and so the results of this very long-term priming condition are not presented in full. Briefly, repetition priming for real (low-frequency) words in lexical decision was found to be substantial and stable over time [mean across all delays $=26 \mathrm{msec}$, which was significantly above zero, $t(23)=2.51, p<.05$, with no correlation across subjects between time delay and priming, $r=-.01]$. Very long term priming for nonwords in lexical decision was found to be initially smaller and to decay over time [mean across all delays $=12 \mathrm{msec}$, which was not significantly above zero, $t(23)=0.86, p>.2$, with a negative correlation between time delay and priming, $r=-.51, p<.05]$.

5. Experiment 2 also had a more satisfactory arrangement of interfering item lexicality than the experiments previously reported (see footnote 2 of McKone, 1995). There, most or all intervening items at Lag 1 were words, for both word and nonword targets. Here, $9 / 17$ were words, and 8/1 7 were nonwords, for both word and nonword targets.

(Manuscript received February 7, 1997; revision accepted for publication May 16, 1997.) 